\title{
Em busca de um conceito pretérito de Jornalismo
}

\author{
Franco IACOMINI JUNIOR ${ }^{1}$ \\ Tarcis PRADO JUNIOR ${ }^{2}$ \\ Moisés CARDOSO ${ }^{3}$
}

Resumo:

Este artigo se propõe a buscar uma melhor compreensão dos antecedentes históricos da prática jornalística, utilizando-se para isso de categorias de análise contemporâneas. São levados em conta trabalhos de Mark Deuze e Tamara Witschge, além de Josh Stearns e o conceito de jornalismo formulado por Luiz Beltrão. Conclui-se que o conceito de "atos de jornalismo", usado na atualidade para tentar definir o que seria jornalismo em mutação do século XXI, pode ser aplicado à produção do passado. Assim, a forma de agir e o comportamento do jornalista contemporâneo podem servir de parâmetro para compreender manifestações antigas do jornalismo.

Palavras-chave:

Jornalismo líquido. Atos de jornalismo. Protojornalismo. História da comunicação.

\section{In search of a past concept of Journalism}

\begin{abstract}
:
This paper seeks a better understanding of the historical background of journalistic practice, using contemporary analysis categories. It takes into account works by Mark Deuze and Tamara Witschge, as well as Josh Stearns and the concept of journalism formulated by Luiz Beltrão. Conclusions point that the concept of "acts of journalism", used nowadays to define what would be 21 st century mutating journalism, can be applied to the production of the past. Thus, the way of acting and the behavior of the contemporary journalist can serve as a parameter to understand early manifestations of journalism.
\end{abstract}

Keywords:

Liquid journalism. Acts of journalism. Protojournalism. History of communication.

\section{En busca de un concepto pretérito de Periodismo}

\begin{abstract}
Resumen:
Este artículo se propone buscar una mejor comprensión de los antecedentes históricos de la práctica periodística, utilizando para eso categorías de análisis contemporáneas. Se toman en cuenta trabajos de Mark Deuze y Tamara Witschge, además de Josh Stearns y el concepto de periodismo formulado por Luiz Beltrão. Se concluye que el concepto de "actos de periodismo", utilizado en la actualidad para intentar definir lo que sería el periodismo en mutación del siglo XXI, puede ser aplicado a la producción del pasado. Así, la forma de actuar y el comportamiento del periodista contemporáneo pueden servir de parámetro para comprender manifestaciones antiguas del periodismo.
\end{abstract}

Palabras clave:

Periodismo líquido. Actos de periodismo. Protoperiodismo. Historia de la comunicación.

\footnotetext{
${ }^{1}$ Jornalista, mestre em Teologia, doutor em Comunicação e Linguagens. Professor na Universidade Estadual do Centro-Oeste (Unicentro). Membro do grupo de pesquisa Jor XXI da Universidade Tuiuti do Paraná (UTP). E-mail: fiacomini@gmail.com

${ }^{2}$ Bacharel em Comunicação Social/Relações Públicas, mestre em Saúde Pública e doutor em Comunicação e Linguagens. Professor de graduação e na Universidade Tuiuti do Paraná (UTP). Membro do grupo de pesquisa Jor XXI da UTP. E-mail: tarcisjr@yahoo.com.br

${ }_{3}^{3}$ Publicitário e jornalista, mestre em Desenvolvimento Regional e doutorando em Comunicação e Linguagens (UTP). Professor na Universidade Regional de Blumenau (Furb). Membro do grupo de pesquisa Jor XXI da UTP. E-mail: beiocardoso@gmail.com
} 


\section{Introdução}

O século XXI encontrou a imprensa e os jornalistas em uma situação peculiar, em que a quantidade de dúvidas sobre a sua atividade desafia o conhecimento acumulado pela pesquisa nas últimas décadas. $\mathrm{O}$ advento da comunicação on-line e a fluidez das fronteiras de atuação do produtor de conteúdo e do consumidor da notícia vêm exigindo novas definições e novas formas de pensar.

O objetivo deste artigo é trazer uma contribuição a esses debates, refletindo não só sobre o presente e o futuro do jornalismo, mas também sobre seu passado profundo. Ao pensar sobre a filosofia do jornalismo e seus antecedentes históricos, pretende-se responder às seguintes questões: a lógica do jornalismo pós-industrial do século XXI é, de alguma forma, semelhante às manifestações jornalísticas mais antigas? Em caso positivo, quais seriam essas aproximações?

O tema das novas manifestações do jornalismo contemporâneo tem sido largamente estudado, tanto no Brasil como fora dele. Entre os pesquisadores que se debruçaram sobre o tema estão Mark Deuze e Tamara Witschge (2016), além de Josh Stearns (2013), que serão citados oportunamente neste artigo. Trabalhos sobre a relação do jornalismo com a modernidade líquida descrita por Zygmunt Bauman foram feitos por Deuze (2008) e por outros, inclusive Anelise Rublescki (2011), que definiu o jornalismo líquido como "um cenário instável, em aberto, permeado por um contínuo de mudanças que aparentemente desencadeiam um processo de alargamento das fronteiras do campo, cujo ponto de equilíbrio ainda é uma questão que permanece em aberto" (RUBLESCKI; SILVA, 2012, p. 119).

Caracteriza-se a presente pesquisa como de abordagem qualitativa. Quanto aos procedimentos técnicos, o trabalho é referente a uma pesquisa bibliográfica (conforme Marconi e Lakatos, 2003) acerca da história do jornalismo e dos seus desenvolvimentos atuais. O presente artigo está estruturado em Introdução, Pressupostos Teóricos, Desenvolvimento Histórico e Considerações Finais.

\section{Pressupostos teóricos}

Nos pressupostos teóricos deste artigo serão tratados três temas: o conceito de jornalismo, tendo como ponto de partida a definição construída por Luiz Beltrão (1992); suas mutações no século XXI, tendo como referência artigos de Mark Deuze (2008) e do 
autor em parceria com Tamara Witschge (2015 e 2016); e os trabalhos de Jürgen Habermas (1989, 2003 2012) sobre a esfera pública e a ação comunicativa.

O conceito sobre o que é jornalismo foi desenvolvido e solidificado ao longo de alguns séculos, até estar relativamente bem estabelecido e desfrutando de relevância na sociedade na segunda metade do século XX (BELTRÃO, 1992). Não é, entretanto, uma definição simples, dadas as formas complexas que a atividade vinha atingindo - diferentes formas de distribuição, abordagens, focos, entre outras distinções. Beltrão (1992, p. 60) ressalta a existência de numerosas tentativas de definir o jornalismo, algumas baseadas em argumentos práticos, outras em formas literárias ou, ainda, baseadas apenas em argumentação. Ele próprio prefere se ater às características fundamentais e elaborar algo bem mais simples: "Diremos, primeiro, que fazer jornalismo é informar". Trata-se de um caminho bastante abrangente, e o pesquisador brasileiro apresenta recortes que encaminham a questão para uma definição um pouco mais fechada e mais "nobre":

Mas "não é função da imprensa" (compreendida como jornalismo) informar ligeira e frivolamente sobre os fatos que acontecem ou censurálos com maior soma de afeto ou adesão. Toca à imprensa elogiar, explicar, ensinar, guiar, dirigir; toca-lhe examinar os conflitos e não agravá-los com um juízo apaixonado; não encaminhá-los com alarde de adesão talvez extemporâneo; toca-lhe, enfim, propor soluções, amadurecê-las, torná-las fáceis, submetê-las à censura, reformá-las; tocalhe estabelecer e fundamentar ensinamentos, se pretende que o país a respeite, e que, conforme os seus serviços e merecimentos, a proteja e honre. Assim, os fatos correntes expostos pelo jornalismo têm de ser devidamente interpretados, porquanto "informação, orientação e direção são atributos essenciais do periodismo, que não pode ser substituído nem sequer momentaneamente por nenhum outro agente cultural nesta tarefa junto à sociedade." ${ }^{\prime 4}$ Daí porque a obra jornalística se realiza dia a dia, porque os fatos, devidamente interpretados, têm de ser transmitidos periodicamente não ao indivíduo isolado mas a um conjunto ou à totalidade dos homens que vivem em sociedade. (BELTRÃO, 1992, p. 62)

Assim, Beltrão (1992) se encaminha para um conceito técnico da atividade jornalística, que acaba por definir da seguinte forma:

Jornalismo é a informação de fatos correntes, devidamente interpretados e transmitidos periodicamente à sociedade, com o objetivo de difundir conhecimentos e orientar a opinião pública, no sentido de promover o bem comum. (BELTRÃO, 1992, p. 62)

\footnotetext{
${ }^{4}$ No original, o trecho entre aspas corresponde a uma citação de LA SAURÉE, Octavio. Moralética del periodismo - Una indagación sistemática de la conciencia profesional. La Habana: Cultural, 1946.
} 
Definições como essa têm sido desafiadas pelos desenvolvimentos contemporâneos do jornalismo. Mark Deuze e Tamara Witschge (2015, p. 2) observam, a partir de formulações correntes tanto na cultura popular como no círculo de convivência dos jornalistas, que "o jornalismo é amplamente reconhecido e visto como um conjunto de valores, princípios e práticas aprovados de diferentes formas (e em diferentes contextos) e que possuem um senso de integridade e continuidade". Para os autores, entretanto, tal definição é falaciosa, um "sonho modernista de coerência e consenso", uma realidade diferente das suas autoapresentações e das formas como os próprios estudiosos da comunicação enxergam o campo nesta fase que denominam "jornalismo pós-industrial" (DEUZE; WITSCHGE, 2016, p. 8), por desenvolver-se em uma fase em que redações e emissoras tradicionais encontram-se desafiadas a existir em um ambiente de descentralização e mudança.

O trabalho de Deuze e Witschge (2016, p. 8) aponta para um entendimento diferente do jornalismo, menos estável e mais fluido: "algo semelhante a um 'tornar-se', em vez de um ser”. Em outras palavras, o foco deixa de ser o produto - que, na era clássica do jornalismo do século XX esteve primariamente ligado à produção feita por jornalistas dentro de empresas especializadas, que constituíam seu ambiente principal de trabalho - e passa ao jornalista e ao seu modo de trabalhar. Assim, o jornalismo articula-se como uma cultura ou uma ideologia ocupacional capaz de ser resumida em cinco itens, os quais serviriam para dar unidade à profissão e defendê-la contra ameaças:

Jornalistas tenderiam a espelharem-se uns nos outros nessas normas típico-ideais, vendo a si próprios como (a) fornecedores de um serviço público; (b) imparciais, neutros, objetivos, justos e críveis; (c) trabalhadores autônomos, livres e independentes; (d) comprometidos com uma lógica operacional do imediatismo, da realidade e da velocidade (proeminente no conceito de furo noticioso); e (e) com um senso de ética, validade e legitimidade. (DEUZE; WITSCHGE, 2016, p. 13)

Deuze argumenta que, em consequência dessa cultura e ideologia comuns, a representação dos jornalistas na sociedade - que é, de fato, produzida pelos próprios jornalistas por meio de expressões autorreferenciadas, como biografias, memórias e hagiografias (DEUZE; WITSCHGE, 2015) - tende a manter-se a mesma, ainda que suas condições de atuação mudem rapidamente. Essa estabilidade do exercício profissional do jornalismo é, frequentemente, compreendida como um componente importante para as relações entre as instituições, uma forma de mediação que toma o papel de uma argamassa que dá solidez à sociedade (DEUZE, 2008). 
A pretensão parece fora de contexto, fruto de outra época, ainda de acordo com Deuze (2008):

Considerando a tendência entre os trabalhadores na notícia de reiterar e produzir valores antigos, ao mesmo tempo em que surfam as ondas de mudança permanente, amplificada pelas atitudes e comportamentos da elite financeira e política global, o jornalismo justifica uma modernidade que parece perturbadora, na melhor das hipóteses, e fora da realidade cotidiana da maior parte de seus habitantes, na pior. (DEUZE, 2008, p. 850)

Deuze recorre ao conceito de modernidade líquida de Zygmunt Bauman ${ }^{5}$ para explicar a situação do jornalismo destes primeiros anos do século XXI, definidos pela "permanente impermanência" da indústria da comunicação (DEUZE; WITSCHGE, 2016, p. 8), resultando em um "jornalismo líquido", em que a participação da audiência e os diversos contextos de consumo e reuso das mensagens mudam a maneira como a comunicação é percebida (DEUZE, 2008).

Posto, então, que o jornalismo deve ser entendido mais a partir da ação e motivação dos jornalistas do que do produto em si, torna-se necessário afastar-se da concepção técnica que se estabeleceu nos últimos 100 ou 150 anos e aproximar-se mais das razões e processos que envolvem a comunicação em si. Para tanto, recorre-se neste artigo às ideias de Jürgen Habermas sobre o agir comunicativo. Segundo Roseli Figaro (2010, p. 59), o objetivo de Habermas foi "afastar-se da concepção de razão técnica para retomar o conceito de razão em sua potencialidade humanista e civilizadora do projeto iluminista".

Um dos pontos essenciais do raciocínio habermasiano em sua teoria social crítica é a construção de um conceito de sociedade em dois níveis, que são os paradigmas do sistema e do mundo da vida. É nesse contexto que surge a ação comunicativa: "O mundo da vida se reproduz mediante ações comunicativas de indivíduos que dele fazem parte durante o tempo em que se nutrem de um pano de fundo - que é também mundo da vida -, o qual se articula em linguagem!” (HABERMAS, 2012, p. 196). É em meio a essas relações intersubjetivas que os discursos são articulados e é por elas que se busca o entendimento e o conhecimento sobre os quais o jornalismo atua e é construído.

\section{Desenvolvimento histórico}

\footnotetext{
${ }^{5}$ De acordo com Bauman (2007, p. 7), "líquido-moderna é uma sociedade em que as condições sob as quais seus membros agem mudam num tempo mais curto do que aquele necessário para a consolidação, em hábitos e rotinas, das formas de agir". A percepção dessa constante mudança social e tecnológica é, então, condição para o entendimento dessa sociedade.
} 
Conforme Josh Stearns (2013), a imagem do jornalista profissional consolidou-se no início do século XX. Essa imagem era a de um indivíduo engajado em uma organização jornalística, que tinha como característica a disseminação periódica de informações, sob formas reconhecidas: impressas sobre papel, narradas pelo rádio, apresentada nas imagens animadas de telejornais ou cinejornais.

Além disso, essa atuação tinha uma arena conhecida, a redação, centro nevrálgico das decisões nas empresas jornalísticas e local de trabalho do jornalista (DEUZE; WITSCHGE, 2015, p. 9). Essa superioridade da redação foi sacramentada até mesmo pela cultura popular: não é por outra razão que super-heróis como o Super-Homem e o Homem Aranha trabalhavam em empresas jornalísticas. Na mitologia criada sobre o trabalho jornalístico, era para elas que afluía toda informação, concedendo aos paladinos da justiça acesso a quaisquer situações que necessitassem sua intervenção, em qualquer lugar do mundo. Essas manifestações populares ajudaram a construir a cultura ocupacional do jornalista e, junto a relatos reais de reportagens, contribuíram para a formação das "hagiografias"6 mencionadas por Deuze e Witschge, citadas anteriormente.

Essa autoimagem propagada pelos jornalistas, entretanto, era desafiada de tempos em tempos pela ação essencial de não-jornalistas que, por se colocarem em um ponto de observação privilegiado, tornam-se testemunhas oculares da história. Os casos da metragem filmada em 8 milímetros por Abraham Zapruder, mostrando o assassinato de John Kennedy, e do vídeo feito por George Holliday em 1991, revelando o espancamento do motorista de táxi negro Rodney King por um grupo de policiais - ambos considerados antecedentes da linha conhecida por citizen journalism (ALLAN, 2013, p. 84) -, podem ser citados entre esses momentos em que pessoas "comuns" (ou seja, indivíduos que não eram profissionais da imprensa) atuaram de forma a tornar públicas informações que podem ser classificadas como fatos noticiosos.

Dan Gillmor observa que, como resultado desses processos, a linha fronteiriça entre produtores e consumidores tende a se desbotar, "provocando alterações que só agora começamos a antever, nos papéis de cada um dos grupos" (GILLMOR, 2005, p. 15). Ao mesmo tempo, instituições que não carregavam em si a tradição jornalística, como organizações de defesa de direitos humanos e do meio-ambiente passaram a adotar

\footnotetext{
${ }^{6} \mathrm{Na}$ tradição católico-romana, as hagiografias são biografias literárias de santos ou escritos a respeito deles, com ênfase a aspectos exemplares de sua vida (CERTEAU, 1982). Por extensão (e esse é o sentido em que Deuze e Witschge emprega a expressão), elas podem ser compreendidas como relatos capazes de construir uma imagem exemplar de um indivíduo ou grupo de indivíduos.
} 
procedimentos e rigores típicos da reportagem em suas ações, conforme defende o mesmo autor, em artigo mais recente. "Eles não estão todos fazendo jornalismo, que fique claro. Mas não é hora de reconhecer o jornalismo, onde quer que seja feito e por quem quer que seja feito?" (GILLMOR, 2014).

Talvez como consequência de todas essas novidades, a aura de centro de inteligência construída em torno das redações também vem se apagando. Deuze e Witschge (2015, p. 9) observam que, nessa época de jornalismo pós-industrial, "grande parte da coleta, edição e empacotamento das notícias ocorre em outro lugar, fora da sala de redação e em organizações que virtualizam o seu fluxo de trabalho, delegando atividades para repórteres e correspondentes que estão na rua”. E muitos dos profissionais envolvidos nesse processo - na redação ou fora dela - não são exatamente jornalistas na acepção que se dava ao termo no século passado, mas curadores de conteúdo, gestores de redes sociais, editores de áudio e vídeo, frutos de um jornalismo convergente. Os mesmos autores, em outro artigo, escrevem que as definições de jornalismo e de jornalista podem ser entendidas "tanto em termos ideológicos quanto praxeológicos e não são mais dependentes do trabalho realizado dentro de instituições" (DEUZE; WITSCHGE, 2016, p. 10).

Nessa atual conformação, torna-se importante redefinir alguns conceitos, inclusive para estender a todas as manifestações jornalísticas as proteções legais de que desfruta a imprensa tradicional. Na visão de Stearns (2013), ao tornar demasiado restrita a definição de quem é jornalista, corre-se o risco de excluir, por exemplo, o jornalismo cidadão, os jornalistas independentes e sites de denúncia. O resultado disso seria um prejuízo à oferta de informação para o público. Entre acadêmicos, parlamentares e magistrados dos Estados Unidos, sedimenta-se a ideia de que a proteção não deve se limitar a uma categoria profissional previamente identificável - o jornalista -, mas deve se estender a qualquer pessoa cuja atuação inclua "atos de jornalismo" (STEARNS, 2013, p. 2).

Esses atos são de difícil conceituação. A partir de debates recentes entre jornalistas e estudiosos a respeito da proteção legal à atividade jornalística, Stearns (2013) enumera três características que, embora não sejam definidoras, apontam caminhos para reconhecer o jornalismo nas diversas elaborações da comunicação humana. Nenhum deles explica totalmente o que seria um ato de jornalismo, mas, aplicados em conjunto, eles podem servir como referência. Em primeiro lugar, de acordo com o autor, o jornalismo é enraizado na ética. Isso significa que a ação do jornalista não se vale da liberdade de opinião que a maioria dos países garante aos cidadãos para obter algum tipo de vantagem 
pessoal ou corporativa. Em lugar disso, suas atitudes têm como referência um certo conjunto de práticas e de padrões. Suas relações com governo, líderes da política e da iniciativa privada também prezam pela autonomia de ação (STEARNS, 2013).

Em segundo lugar, jornalismo tem a ver com comportamento: "Se jornalismo é um ato, então talvez nós devamos ser julgados pela forma como agimos" (STEARNS, 2013, p. 10) - esse seria o fator "praxeológico", para usar um termo de Deuze e Witschge, citados anteriormente. Stearns relembra as observações de Steve Myers, ex-editor do website do Poynter Institute, a respeito do cidadão paquistanês Sohaib Athar, que descreveu pela rede social Twitter a operação militar que, como ficaria claro mais tarde, resultou na morte de Osama bin Laden. Myers (2011) defende que, em tempos anteriores, o jornalismo poderia ser reconhecido por seu produto final, ao passo que as tecnologias presentes na atualidade permitem reconhecê-lo enquanto é produzido, pela sua atividade. Assim, Athar portou-se como jornalista porque observou algo incomum e relatou isso a outros; respondeu questões de outras pessoas em busca de informação; atuou como um condutor de informações, partilhando informações à medida que as obtinha; buscou relatos de outras fontes e os compartilhou; trocou informações a fim de descobrir o que estava acontecendo; e teceu análises sobre os eventos que relatava. Esse, segundo Myers (2011) e também Stearns (2013), seria o comportamento esperado em um jornalista em situação semelhante.

A terceira e última característica é que o jornalismo é um serviço prestado ao público: o serviço de disseminar informação a um público amplo, de modo que elas possam reunir conhecimento e organizar-se. Para Stearns (2013), todo ato de jornalismo incorpora elementos dessas três definições parciais, de modo complexo e, muitas vezes, também de uma maneira inconsciente. Tal complexidade foi adotada na definição que consta de um projeto de lei em discussão no Congresso dos Estados Unidos. De acordo com o projeto, o jornalismo seria definido por atos que compreendem "coleta, preparo, organização, fotografia, gravação, redação, edição, relato ou publicação de notícias ou informação de eventos de interesse local, nacional ou internacional ou de outros temas de interesse público para disseminação ao público".7

\footnotetext{
7 O texto citado faz parte do Free Flow of Information Act, uma proposta de legislação para garantir proteção federal ao exercício do jornalismo nos Estados Unidos, em especial no que concerne ao sigilo de fontes. Embora existam leis estaduais concedendo esse privilégio legal, não há naquele país norma federal nesse sentido. O texto completo da proposta pode ser encontrado em https://www.congress.gov/bill/113thcongress/house-bill/1962/related-bills. Para um melhor entendimento da questão, a Society of Professional Journalists tem uma seção em seu website dedicada ao tema das leis de proteção aos jornalistas (conhecidas em inglês como shield laws): https://www.spj.org/shieldlaw-faq.asp.
} 
Incluem-se nessa categoria diversos tipos de iniciativas. Stearns cita como exemplares os casos de uma jovem estudante que filmou com seu celular uma abordagem policial, um urbanista que reúne informações sobre tempestades em uma página na rede social Facebook e um historiador amador que levantou informações inéditas sobre o fundador de sua cidade natal. "Ao redor do país, pessoas estão praticando atos de jornalismo que estão servindo suas comunidades, influenciando o debate nacional e mudando a face do jornalismo", escreve (STEARNS, 2013, p. 1).

Essa conformação difere radicalmente do que se entendia há um século, conforme explicitado anteriormente. Mas seriam essas novas conformações uma surpreendente configuração em uma instituição social reconhecida, ou um fenômeno previsível ou mesmo esperado? Havia atos de jornalismo também no passado?

Na opinião de Anelise Rublescki e Alexandre Rocha da Silva, não se deve (ou não se deveria) esperar da atividade jornalística uma solidez em suas práticas e atribuições:

Mutações fazem parte da própria história do Jornalismo, posto que prática sociocomunicacional. $\mathrm{O}$ mesmo se aplica à notícia, entendida como a narrativa de acontecimentos sociais. Mutável como o próprio Jornalismo, a notícia se adaptou aos suportes e deles fez distintos meios de expressão. Mudou junto com os modos de produção, com a cultura profissional e com as organizações jornalísticas. No processo, passou por diferentes etapas; mutou em forma, gêneros e critérios de relevância e se adaptou tanto às opções tecnológicas dos diferentes períodos quanto às diversas configurações socioculturais. Nos diferentes períodos, os preceitos do campo se modificaram. Enquanto prática social, novos conceitos de notícia emergiram. (RUBLESCKI; SILVA, 2012, p. 128)

Ou seja: analisado de perto, o Jornalismo é muito mais mutável e adaptativo do que se poderia supor a partir da autoimagem construída nos últimos 100 ou 200 anos. Assim, não seria incorreto supor que esses atos de jornalismo, entendidos na sua essência, tenham assumido diversas formas ao longo da história da humanidade. Conforme descreve Carlos Rizzini (1977), diversos suportes precederam o papel e a tinta na difusão de informações entre as pessoas, por meio de letras ou símbolos. Muitas delas não caberiam na definição de registro histórico ou relato pessoal, parecendo-se mais com colunas de jornal. É assim que o autor se refere às histórias de curas apresentadas em estelas de pedra preservadas no oráculo de Esculápio, deus da Medicina, na localidade grega de Epidauro (RIZZINI, 1977).

No contexto de Epidauro, portanto, aquilo que poderia ser entendido como "notícia" para aquele público específico - doentes que peregrinavam de diversas localidades da Europa e da Ásia Menor em busca de esperança - era disseminado por 
interesse religiosos. Os "atos de jornalismo" poderiam ser vinculados a finalidades diferentes, mas teriam a mesma essência informativa. Assim, escreve Rizzini (1977):

A transmissão oral, o periódico imóvel, a carta particular, na Antiguidade; o jogralismo e o trovadorismo palaciano e ambulante, e as crônicas, na Idade Média; de novo a carta particular, a carta destinada ao público e a carta-de-notícias, o novelismo-de-boca, de café e de rua, a sátira verbal, a escrita, em prosa ou em verso, o pasquim, e, por fim, a gazeta-a-mão, no Renascimento e na Idade Moderna - constituem os processos históricos do jornalismo antes da tipografia. (RIZZINI, 1977, p. $\mathrm{XV})$

Rizzini descreve um mercado de notícias extremamente ativo na Europa do século XVIII, largamente baseado em gazetas manuscritas passadas de mão em mão em Londres, Paris e Lisboa, entre outras grandes cidades. Tal noticiário era, então, contextualizado, ampliado e disseminado em bares, cafés e nas ruas, verdadeiras "bolsas de notícias", à semelhança da agitação comercial provocada nas incipientes bolsas de mercadorias da época. Recuando ainda mais na história do jornalismo (ou de um protojornalismo, no sentido de ser um antecedente ainda não totalmente formado ou reconhecível como tal), autores como Bice Mortara Garavelli (1991) apontam similaridades na forma de escrever do jornalismo contemporâneo (em especial, o uso do lide) com antigos retóricos gregos e latinos. Jorge Pedro Sousa (s.d.) vai adiante e aponta pontos de contato entre os diários atuais e relatos do Antigo Testamento e de obras clássicas de Homero, entre outros.

O antecedente histórico das fórmulas de escrita pode ser visto como uma curiosidade histórica e literária. Mais importante para o entendimento de um recorte histórico do jornalismo é o desenvolvimento da ideia do jornalismo em si. Conforme observa Francisco Karam (2009):

Quando tratamos do lead e das narrativas, quando falamos de linguagens e ideologia, poderíamos buscar, na antiguidade greco-romana - e não no que errônea e pejorativamente chama-se hoje de "tecnicismo" -, as bases ontológicas do surgimento da atividade específica; as bases morais da ética da palavra e da profissão jornalística, mesmo que a sociedade de então, por tempo, cultura, ritmo e demais razões óbvias, sequer pudesse conceber qualquer vestígio futuro do hoje chamado jornalismo. (KARAM, 2009, p. 115)

Mitchell Stephens (1993), recorrendo a estudos de etnografia feitos na segunda metade do século XX, observa que culturas ágrafas e letradas demonstram igual avidez em conhecer as últimas novidades. Ele conclui que esses achados apontam para uma necessidade humana primordial pelo conhecimento e pelo relacionamento, de forma que as pessoas reconhecem-se nas histórias que ouvem e, desse modo, valorizam seus 
relacionamentos. Tal desenvolvimento corresponde, de alguma forma, à observação (cuja abrangência parece ser universal) feita por Habermas a respeito do papel da linguagem no mundo da vida:

[...] a ação comunicativa pressupõe a linguagem como um meio dentro do qual tem lugar um tipo de processo de entendimento, em cujo transcurso os participantes, ao relacionar-se com um mundo, se apresentam uns frente aos outros com pretensões de validade que podem ser reconhecidas ou postas em questão. (HABERMAS, 2012, p. 163)

Para traçar os primórdios do jornalismo é, preciso, naturalmente, buscar registros escritos. Para Sousa (s.d.), essa busca deve iniciar-se nos antigos gregos, porque eles deram partida à formação do jeito de ser do jornalista:

A retórica, ligada à política e ao direito (vida nos tribunais), a literatura, a historiografia e os relatos geográficos e etnográficos foram, assim, alguns dos contributos dos antigos gregos para a fixação, muitos séculos depois, dos valores e formas de agir dos jornalistas, bem como para a definição dos formatos e dos conteúdos jornalísticos, ou seja, para a fixação das estruturas típicas das matérias jornalísticas e dos temas abordados pelo jornalismo. (SOUSA, s.d., p. 7, grifos do autor)

Assim, os "valores" e "formas de agir" dos jornalistas, bem como um certo conjunto de temas típicos, apontam para o caminho para reconhecer o protojornalismo. Sousa (s.d.) prossegue, destacando os relatos de Tucídides sobre a Guerra do Peloponeso e o fato de ser este o primeiro a avaliar suas fontes com espírito crítico e a buscar as razões reais dos conflitos, por trás das aparências e dos pretextos dos monarcas. De alguma forma, os conceitos usados por Tucídides parecem se aproximar daquelas categorias definidoras do ato de jornalismo na contemporaneidade, citados anteriormente por Stearns: ética, comportamento e serviço.

Mais do que isso: bastante cedo, alguns autores da Antiguidade Clássica apresentavam críticas importantes à forma como se relatavam os fatos no seu tempo. Tais escritos são tratados atualmente como estudos historiográficos pioneiros, mas podem ser entendidos de forma diferente, já que se referiam a eventos contemporâneos mais do que ao que, hoje, se costuma rotular como a História com letra maiúscula. Tucídides mesmo aponta divergências com outros escritores contemporâneos, como na passagem a seguir, geralmente apontada como uma crítica a Heródoto e a outros que o precederam:

À luz da evidência apresentada até agora, todavia, ninguém erraria se mantivesse o ponto de vista de que os fatos na antiguidade foram muito próximos de como os descrevi, não dando muito crédito, de um lado, às versões que os poetas cantaram, adornando e amplificando os seus temas, 
e de outro considerando que os logógrafos ${ }^{8}$ compuseram as suas obras mais com a intenção de agradar aos ouvidos que de dizer a verdade uma vez que suas estórias não podem ser verificadas, e eles em sua maioria enveredaram, com o passar do tempo, para a região da fábula, perdendo, assim, a credibilidade. (TUCÍDIDES, 2001, p. 13).

Luciano de Samósata dedica boa parte de seu tratado satírico Como se deve escrever a história ao que se poderia chamar de contraexemplos, nos quais sublinha o modo de agir dos maus historiadores. Ao analisar os escritos de Luciano, o historiador André Leme Lopes aponta qual seria o principal ponto de tensão do opúsculo, que é a crítica do escritor helênico aos cronistas que favoreciam o império romano em seus relatos, mais preocupados em receber os benefícios reservados aos aduladores que com a precisão de suas descrições. "A oposição central de Como se deve escrever a história não é, portanto, entre verdade e mentira, como poderíamos pensar inicialmente; é entre verdade e adulação, pois a história era um assunto político que exigia imparcialidade e justiça", escreveu (LOPES, 2005, p. 191, grifo do autor).

\section{Conclusões}

Ao longo deste artigo, foi abordada a questão essencial acerca de como identificar e definir o que é jornalismo na contemporaneidade, com destaque para a definição dos atos de jornalismo, entendidos como ações definidoras que podem ser tomadas inclusive por pessoas sem relação com empresas jornalísticas. Abordou-se ainda a forma como uma cultura ou ideologia ocupacional do jornalismo se estabeleceu e o seu resultado, que foi o da formação de uma imagem do jornalismo baseada na atuação dentro de um tipo de empresa e um ambiente típico de trabalho. Em seguida, passou-se à discussão da validade histórica desse conceito, recorrendo-se às observações de autores como Carlos Rizzini, Jorge Pedro Sousa e Francisco Karam.

Ao entrar nestas considerações finais, retorna-se à questão teórica que esta pesquisa pretende responder: a lógica do jornalismo pós-industrial do século XXI é, de alguma forma, semelhante às manifestações pré-jornalísticas? À luz dos autores estudados, a resposta à primeira questão parece ser positiva, visto que a ideia básica dos atos de jornalismo demonstra ser aplicável a escritos que remontam à Antiguidade (caso das referências de Sousa a Tucídides, já citado, e a Xenofonte, ou ainda de outros autores clássicos, como Políbio e Luciano de Samósata).

\footnotetext{
${ }^{8}$ Os antigos historiadores eram chamados de "logógrafos", uma expressão que Tucídides usa com tom pejorativo (TUCÍDIDES, 2001, p. 14).
} 
Quais seriam, então, as aproximações entre $\mathrm{o}$ fazer jornalístico da contemporaneidade e essas manifestações pré-jornalísticas ou protojornalísticas?

Seria simples observar, como fizeram outros, semelhanças no modo de escrever dos jornalistas hodiernos com o estilo de peças literárias do passado. Além de repetitivo, tal exercício seria falacioso, pois ignora a influência das tradições na formação dos gêneros jornalísticos. Não seria por coincidência histórica que os retóricos latinos e os poetas épicos gregos usavam estruturas textuais que lembram a força decrescente das narrativas em pirâmide invertida, consolidadas como referência para o texto jornalístico pelas agências de notícias do século XX. A semelhança também não se explica por algum tipo de resgate literário, mas pela influência acumulada de séculos de relatos, discursos e argumentações. Ao serem forçados a escolher uma forma de apresentar suas informações em uma situação em que a concisão era essencial, os jornalistas reencontraram caminhos antes traçados e consagrados por referenciais antigos, provenientes da História, da literatura ficcional e de outras fontes. A análise do fenômeno literário da linguagem jornalística encontra-se em harmonia com o entendimento do jornalismo como um fenômeno da Idade Moderna - justamente aquela leitura que, perpetuada como um anacronismo ao longo do século XX, é questionada diante do quadro líquido que se apresenta na atualidade.

Ademais, a escrita é mero meio para difusão do jornalismo, não o jornalismo em si. Seu coração estaria em uma "filosofia do jornalismo" (conforme Beltrão) ou em uma ideologia ocupacional (conforme Deuze), capazes de sobreviver à "permanente impermanência" que caracteriza a atividade. Na prática, reflete-se em formas de ação que podem ser tipificadas nos atos de jornalismo, cujas características, listadas por Stearns, combinam com as normas definidoras da cultura jornalística, descritas por Deuze e Witschge.

O reconhecimento de um quadro de atributos classificáveis como atos de jornalismo é uma ferramenta capaz de elucidar não somente os impasses a que a academia se depara hoje, mas também para encontrar caminhos para a compreensão do jornalismo pretérito. Esses elementos estão presentes na atualidade e são difundidos, muitas vezes, por meio de dispositivos que usam a tecnologia digital mais avançada. Mas as motivações das pessoas que agem dentro desse conceito jornalístico são semelhantes àquelas que moviam autores do passado. 
Observe-se, por exemplo, o trecho de A História da Guerra do Peloponeso, de Tucídides, citado anteriormente, parte de um trecho mais amplo, que trata da maneira como ele compôs sua obra, uma espécie de declaração de propósito do trabalho. O segmento encerra-se no capítulo 22 do livro I:

O empenho em apurar os fatos se constituiu numa tarefa laboriosa, pois as testemunhas oculares de vários eventos nem sempre faziam os mesmos relatos a respeito das mesmas coisas, mas variavam de acordo com suas simpatias por um lado ou pelo outro, ou de acordo com sua memória. Pode acontecer que a ausência do fabuloso em minha narrativa pareça menos agradável ao ouvido, mas quem quer que deseje ter uma ideia clara tanto dos eventos ocorridos quanto daqueles que algum dia voltarão a ocorrer em circunstâncias idênticas ou semelhantes em consequência de seu conteúdo humano, julgará a minha história útil e isto me bastará. $\mathrm{Na}$ verdade, ela foi feita para ser um patrimônio sempre útil, e não uma composição a ser ouvida apenas no momento da competição por algum prêmio. (TUCÍDIDES, 2001, p. 14-15)

Nos dois trechos citados podem-se encontrar indícios que remetem à noção de atos de jornalismo. Por ser enraizado na ética e comprometido com sua autonomia de ação (a primeira característica descrita por Stearns), Tucídides conta ter buscado relatar os eventos do conflito da forma mais próxima possível da realidade, e demonstra incômodo com aqueles que adornaram e amplificaram o tema, preocupação semelhante à que demonstra Luciano de Samósata quando ironiza os pretensos historiadores que usavam suas obras para obter favores dos poderosos. A finalidade declarada de compor um "patrimônio sempre útil" satisfaz a característica de "serviço destinado ao público" tipificada por Stearns. E o empenho em apurar os fatos e separar deles as declarações que continham simples preferência partidária permite entrever o comportamento típico do jornalista, característica também dos atos de jornalismo.

Há vantagens na continuidade da pesquisa a respeito da formação histórica da ideia de jornalismo. A principal delas será obter uma compreensão mais avançada sobre como a maneira de disseminar notícias no passado resultou nas concepções que os profissionais da comunicação perpetuam ainda hoje, no século XXI - uma espécie de genealogia teórica do jornalismo. Tais análises podem contribuir grandemente tanto para a pesquisa em comunicação quanto para a História, que tem nas "pistas" deixadas pelo jornalismo uma de suas principais fontes de informação sobre o passado.

\section{Referências}

FIGARO, Roseli. Ação comunicativa. In: Enciclopédia INTERCOM de Comunicação. 
São Paulo: Sociedade Brasileira de Estudos Interdisciplinares da Comunicação, 2010. p. 59-60. v. 1.

ALLAN, Stuart. Citizen witnessing: revising journalism in times of crisis. Cambridge: Polity, 2013.

BAUMAN, Zygmunt. Vida líquida. Rio de Janeiro: Jorge Zahar, 2007.

BELTRÃO, Luiz. Iniciação à filosofia do jornalismo. São Paulo: Edusp, 1992. (Clássicos do Jornalismo Brasieiro, 5).

CERTEAU, Michel de. A escrita da História. Rio de Janeiro: Forense Universitária, 1982.

DEUZE, Mark. The changing context of news work: liquid journalism and monitorial citizenship. International Journal of Communication, Los Angeles, n. 2, p. 848-865, 2008. Disponível em: https://ijoc.org/index.php/ijoc/article/viewFile/290/197. Acesso em: $16 / 6 / 2019$.

DEUZE, Mark; WITSCHGE, Tamara. Além do jornalismo. Leituras do Jornalismo, Bauru, ano 2, v. 2, n. 4, p. 1-31, jul./dez. 2015. Disponível em: https://www3.faac.unesp.br/leiturasdojornalismo/index.php/leiturasdojornalismo/article/vie w/74/64. Acesso em: 16 jun. 2019.

DEUZE, Mark; WITSCHGE, Tamara. O que o jornalismo está se tornando. Parágrafo, São Paulo, v. 4, n. 2, p. 6-21, jul./dez. 2016. Disponível em: http://revistaseletronicas.fiamfaam.br/index.php/recicofi/article/download/478/445. Acesso em: 17 jun. 2019.

GARAVELLI, Bice Mortara. Manual de retórica. Madrid: Cátedra, 1991.

GILLMOR, Dan. Journalism Schools Should Educate Non-Journalists and "AlmostJournalists" Too. 22 abr. 2014. Disponível em: http://mediashift.org/2014/04/journalismschools-need-to-educate-non-journalists-and-almost-journalists-too/. Acesso em: 7 jun. 2017.

GILLMOR, Dan. Nós, os media. Lisboa: Editorial Presença, 2005.

HABERMAS, Jürgen. Consciência moral e agir comunicativo. Rio de Janeiro: Tempo Brasileiro, 1989.

HABERMAS, Jürgen. Mudança estrutural na esfera pública. Rio de Janeiro: Tempo Brasileiro, 2003.

HABERMAS, Jürgen. Teoria do agir comunicativo. São Paulo: Martins Fontes, 2012.

KARAM, Francisco José Castilhos. Retórica, Grécia e Roma Antigas: vestígios da futura linguagem jornalística. Alceu, Niteroi, v. 10, n. 19, p. 109-117, jul./dez. 2009. Disponível em: http://revistaalceu-acervo.com.puc-rio.br/media/Alceu19_Karam.pdf. Acesso em: 17 jun. 2019. 
LOPES, André Leme. Moralidade e justiça na historiografia antiga: o "manual" historiográfico de Luciano de Samósata. História, Goiânia, v. 24, n. 2, p. 187-205, 2005. Disponível em: http://www.scielo.br/pdf/his/v24n2/a08v24n2.pdf. Acesso em: 17 jun. 2019.

MARCONI, Marina de Andrade; LAKATOS, Eva Maria. Fundamentos da metodologia científica. 5 ed. São Paulo: Atlas, 2003.

MYERS, Steve. Why the man who tweeted Osama bin Laden raid is a citizen journalist. 5 maio 2011. Disponível em: https://www.poynter.org/2011/why-the-manwho-tweeted-bin-laden-raid-is-a-citizen-journalist/131135/. Acesso em: 23 mar. 2017.

RIZZINI, Carlos. O jornalismo antes da tipografia. São Paulo: Companhia Editora Nacional, 1977.

RUBLESCKI, Anelise. Metamorfoses jornalísticas: leitores e fontes como instâncias coprodutoras de conteúdos no jornalismo líquido. Estudos em Comunicação, Curitiba, $n$. 10, p. 337-354, 2011. Disponível em: http://www.ec.ubi.pt/ec/10/pdf/EC10-2011Dez18.pdf. Acesso em: 17 jun. 2019.

RUBLESCKI, Anelise; SILVA, Alexandre Rocha da. Jornalismo líquido: tendências de ampliação do campo. Brazilian Journalism Research, Brasília, v. 8, n. 1, p. 118-132, 2012. Disponível em: https://bjr.sbpjor.org.br/bjr/article/view/375/363. Acesso em: 17 jun. 2019.

SOUSA, Jorge Pedro. Uma história breve do jornalismo no Ocidente. [S.d.] Disponível em: http://www.bocc.ubi.pt/pag/sousa-jorge-pedro-uma-historia-breve-do-jornalismo-noocidente.pdf. Acesso em: 21 set. 2016.

STEARNS, Josh. Acts of Journalism: Defining Press Freedom in the Digital Age. New York: Free Press, 2013. Disponível em: http://conference.freepress.net/sites/default/files/resources/Acts_of_Journalism_October_2 013.pdf. Acesso em: 17 jun. 2019.

STEPHENS, Mitchell. Uma história das comunicações: dos tantãs aos satélites. Rio de Janeiro: Civilização Brasileira, 1993.

TUCÍDIDES. História da Guerra do Peloponeso. Brasília: Editora Universidade de Brasília; Instituto de Pesquisa em Relações Internacionais, 2001. (Clássicos IPRI, 2).

Submetido em: 15.08.2018

Aprovado em: 08.03.2019 